\title{
Association of initial imaging modality and futile recanalization after thrombectomy
}

\author{
Thomas Raphael Meinel, MD,* Johannes Kaesmacher, MD, * Pascal John Mosimann, MD, David Seiffge, MD, \\ Simon Jung, Pasquale Mordasini, MD, Marcel Arnold, Martina Goeldlin, MD, Steven D. Hajdu, MD, \\ Marta Olivé-Gadea, MD, Christian Maegerlein, MD, Vincent Costalat, Laurent Pierot, \\ Joanna D. Schaafsma, MD, Urs Fischer, * and Jan Gralla*
}

Neurology ${ }^{\circledR}$ 2020;95:e2331-e2342. doi:10.1212/WNL.0000000000010614

\section{Abstract \\ Objective}

To test the hypothesis that selection by initial imaging modality (MRI vs CT) is associated with rate of futile recanalizations (FRs) after mechanical thrombectomy (MT), we assessed this association in a multicenter, retrospective observational registry (BEYOND-SWIFT [Registry for Evaluating Outcome of Acute Ischemic Stroke Patients Treated With Mechanical Thrombectomy], NCT03496064).

\section{Methods}

In 2,011 patients (49.7\% female, median age 73 years [61-81]) included between 2009 and 2017, we performed univariate and multivariate analyses regarding the occurrence of FR. FRs were defined as 90-day modified Rankin Scale (mRS) score 4-6 despite successful recanalization in patients selected by MRI $(\mathrm{n}=690)$ and CT $(\mathrm{n}=1,321)$ with a sensitivity analysis considering only patients with mRS 5-6 as futile.

\section{Results}

MRI as compared to CT resulted in similar rates of subsequent MT (adjusted odds ratio [aOR] 1.048, 95\% confidence interval [CI] 0.677-1.624). Rates of FR were as follows: 571/1,489 (38\%) FR mRS 4-6 including 393/1,489 (26\%) FR mRS 5-6. CT-based selection was associated with increased rates of FRs compared to MRI (44\% [41\%-47\%] vs $29 \%$ [25\%-32\%], $p<$ 0.001; aOR 1.77 [95\% CI 1.25-2.51]). These findings were robust in sensitivity analysis. MRIselected patients had a delay of approximately 30 minutes in workflow metrics in real-world university comprehensive stroke centers. However, functional outcome and mortality were more favorable in patients selected by MRI compared to patients selected with CT.

\section{Conclusions}

CT selection for MT was associated with an increased risk of FRs as compared to MRI selection. Efforts are needed to shorten workflow delays in MRI patients. Further research is needed to clarify the role of the initial imaging modality on FR occurrence and to develop a reliable FR prediction algorithm.

\author{
Correspondence \\ Dr. Fischer \\ urs.fischer@insel.ch
}




\section{Glossary}

AIS = acute ischemic stroke; aOR = adjusted odds ratio; ASPECTS = Alberta Stroke Program Early CT Score; DWI = diffusionweighted imaging; EVT = endovascular treatment; FR = futile recanalization; IVT = IV thrombolysis; $\mathbf{m R S}=$ modified Rankin Scale; $\mathbf{M T}$ = mechanical thrombectomy; $\mathbf{m T I C I}$ = modified Thrombolysis in Cerebral Infarction; NIHSS = NIH Stroke Scale; RCT $=$ randomized controlled trial; $\mathbf{s I C H}=$ symptomatic intracerebral hemorrhage.

Despite the overwhelming efficacy of mechanical thrombectomy (MT) for endovascular treatment of acute ischemic stroke (AIS), up to $25 \%-50 \%$ of patients have a poor longterm outcome (modified Rankin Scale [mRS] score 4-6) despite successful recanalization, a phenomenon termed futile recanalization $(\mathrm{FR}){ }^{1-3}$

From a patient's perspective, being bedridden, incontinent, and requiring constant nursing (mRS 5) or dead (mRS 6) can indeed be assumed to represent a futile outcome. Some, however, might consider moderately severe disability requiring assistance to attend to bodily needs or to walk (mRS 4) an acceptable, nonfutile outcome. From a societal and health economics point of view, given the logistic and economic impact of endovascular treatment, there is a need to reduce $\mathrm{FR}^{2,4}$ Known predictors of FR include age, NIH Stroke Scale (NIHSS) score, ${ }^{2,5}$ procedure time, ${ }^{6}$ and leukoaraiois. ${ }^{7}$ However, the role of the initial imaging modality for patient selection on the rate of FR remains unclear. ${ }^{8} \mathrm{We}$ hypothesized that imaging modality influences decisions regarding which patients to treat by MT hence resulting in a different rate of FR.

The main objectives of this study were to (1) determine the rate of FR in patients undergoing MT selected by MRI vs CT in a large multicenter registry and (2) identify relevant secondary outcomes, such as workflow metrics, symptomatic intracerebral hemorrhage $(\mathrm{sICH})$, mortality, and functional outcome, according to initial imaging modality.

\section{Methods}

\section{Standard protocol approvals, registrations, and patient consents}

Details on the registry (BEYOND-SWIFT [Registry for Evaluating Outcome of Acute Ischemic Stroke Patients Treated With Mechanical Thrombectomy]) are registered at NCT03496064 and further details were published previously. ${ }^{9}$ Patient consent was obtained according to Good Clinical Practice or institutional review board or local or institutional policies.

Briefly, this multicenter, retrospective, international, nonrandomized observational registry was designed to investigate the safety and efficacy of a second-generation market-released neurothrombectomy device in borderline indications for treatment of AIS. In the 2007 period (center Munich), this included treatment with a Solitaire $\mathrm{AB}$ used as retrievable stent. Medtronic provided financial funding of the registry.

Inclusion criteria of the registry were treatment with a Medtronic market-released thrombectomy device for an intracranial large vessel occlusion with attributable neurologic symptoms. Current participation in another clinical trial was the only exclusion criterion. For this analysis, we included all patients from the registry with available information on initial imaging modality. Between $26 \%$ and $90 \%$ of all patients treated by MT at each center during the study timeframe were included in this registry. Choice of imaging modality was center-specific and not specified. Four centers used mainly CT, 2 centers mainly MRI, and the largest center used CT and MRI in equal parts (figure e-1, doi.org/ 10.5061/dryad.f4qrfj6t1). Reasons why patients underwent CT or MRI were not available as a data item in the registry, but were provided by the local principal investigator for the study timeframe (table 1, Dryad, doi.org/10.5061/dryad.f4qrf6t1). Local principal investigators also provided their approach for patient selection in the study timeframe (table 1, Dryad, doi.org/10. 5061/dryad.f4qrfj6t1) and all centers that had access to both modalities based their decisions on a tissue-based approach with somewhat similar indications to perform MT. Cerebral microbleeds were not an absolute contraindication for IV thrombolysis or (IVT) endovascular treatment (EVT) in the centers that used MRI as initial imaging modality. A clear-cut intracranial hemorrhage excluded both IVT and EVT in all centers.

Indications for MRI as opposed to CT included favorable prognostic features (low NIHSS, no contraindications such as vomiting or pacemakers) as well as unfavorable prognostic features (posterior circulation large vessel occlusion including basilar artery occlusion, intubated patients, and unknown onset time). Choice of EVT after imaging was a tissue-based approach in all participating centers, putting slightly different emphasis on NIHSS, time elapsed, infarct core/Alberta Stroke Program Early CT Score (ASPECTS), collaterals, and overall prognosis (table 1, Dryad, doi.org/10.5061/dryad.f4qrff6t1).

\section{Variables and image analysis}

Operators or independent research fellows at each center determined the site of large vessel occlusion and postinterventional recanalization according to the modified Thrombolysis in Cerebral Infarction (mTICI) scale. Successful recanalization was defined as $\mathrm{mTICI} \geq 2 \mathrm{~b}$, representing at least $50 \%$ antegrade angiographic reperfusion downstream of the initially occluded target territory. ${ }^{10}$ Tandem occlusion was defined as an intracranial large vessel occlusion coupled with an ipsilateral 


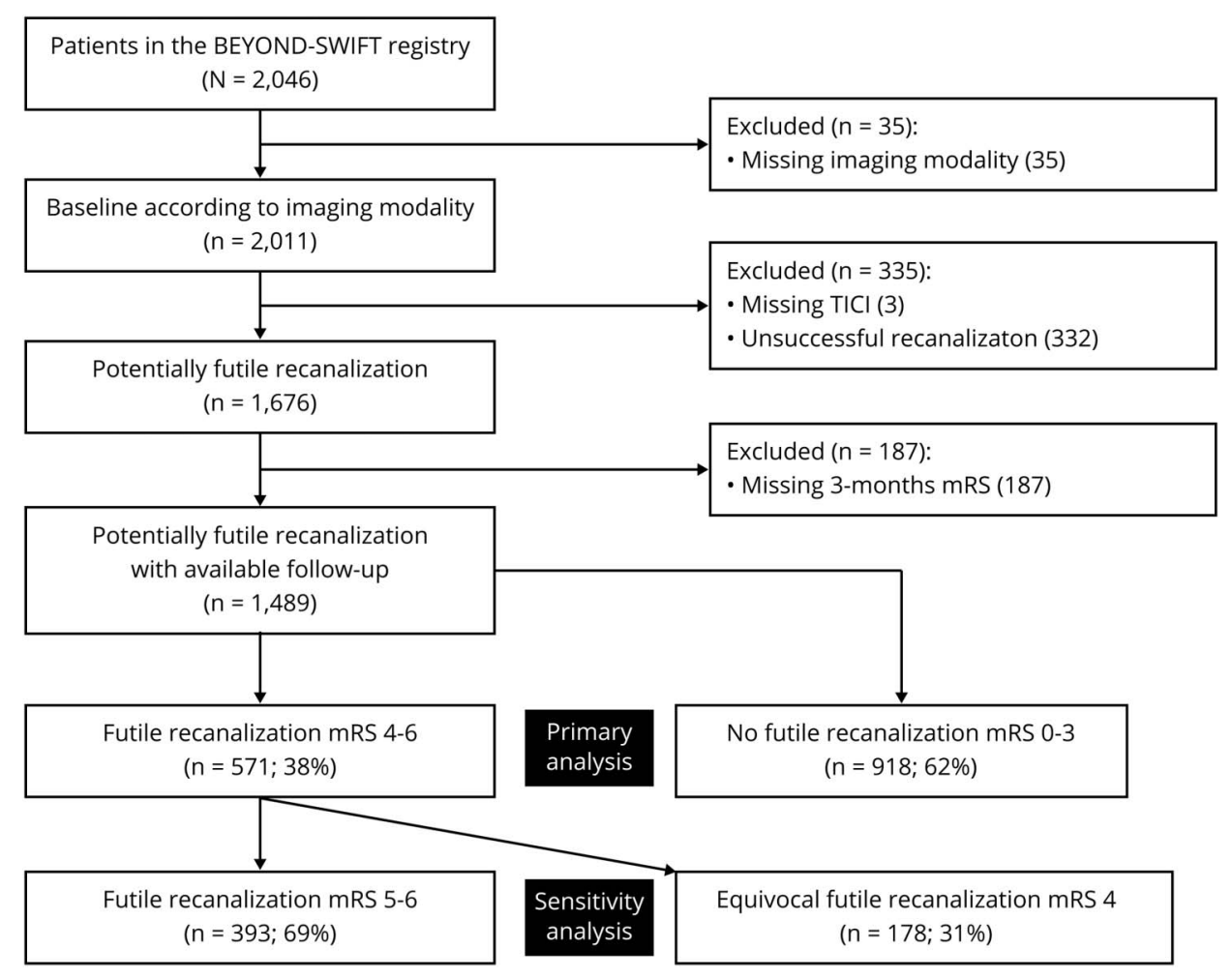

$\mathrm{mRS}=$ modified Rankin Scale; $\mathrm{TICl}=$ Thrombolysis in Cerebral Infarction recanalization score. extracranial occlusion or a stenosis of $90 \%$ or more. For the subgroup analysis of ASPECTS, 1 point was added in MRI patients to correct for the differences in diffusion-weighted imaging (DWI)-ASPECTS as compared to CT-ASPECTS. ${ }^{11}$

\section{Outcomes}

The primary endpoint of this analysis was FR, which was defined as mRS 4-6 at 90 days despite successful endovascular recanalization (mTICI $\geq 2 \mathrm{~b}$ ). ${ }^{12}$ Secondary outcomes included a sensitivity analysis defining FR as mRS 5-6 at 90 days; allcause mortality at 90 days; sICH, which was assessed at each center applying ECASS II (European Cooperative Acute Stroke Study II) criteria $^{13}$; and good functional outcome (mRS 0-2) at 90 days. The mRS score at 90 days was obtained either in routinely scheduled clinical visits or by using standardized telephone interviews.

\section{Statistical analysis}

As patients not undergoing MT were not collected in BEYOND-SWIFT, we sought to address the issue of which parameters were associated with undergoing MT according to each imaging modality in the local database (2015-2018) from the largest participating center (Bern). For this purpose, patients who had a vessel occlusion in the suspected ischemic territory presenting between 0 and 48 hours after symptom onset were compared with univariable analysis as outlined above. A backward stepwise multiple logistic regression analysis was performed to identify factors associated with performing subsequent MT. Then, age, sex, and the imaging modality was added to the model to analyze whether the imaging modality itself was associated with MT decisions.

In the BEYOND-SWIFT dataset, we compared the imaging groups (MRI vs CT) using $\chi^{2}$ and Fisher exact tests for categorical variables, Mann-Whitney $U$ test for non-normally continuous or ordinally scaled variables, and Welsch $t$ test for independent normally distributed data.

For the primary analysis of a preinterventional model, the association of imaging type (MRI vs CT) with all outcome parameters was assessed using multivariable logistic regression adjusting for the following prespecified confounders: age (continuous), sex (categorical), NIHSS on admission (ordinal, adjusted odds ratio [aOR] per point increase), known symptom onset (categorical), prestroke independence ( $\mathrm{mRS} 0-2$; categorical), hypertension (categorical), diabetes (categorical), smoking (categorical), previous stroke (categorical), center (categorical, contrast type: comparator; indicator: largest center), anterior vs posterior circulation (categorical), time from symptom onset to groin puncture (continuous), and IV thrombolysis (categorical). For the prognostic postinterventional model, the following additional confounders were included: TICI 3 vs TICI $2 b$ (categorical), use of balloon guiding catheter (categorical), intracranial stenting (categorical), general anesthesia (categorical), time from groin puncture to recanalization (continuous), and number of passes (ordinal, aOR per pass). The rationale for both models was the 
Table 1 Baseline characteristics of patients according to initial imaging modality

\begin{tabular}{|c|c|c|c|c|}
\hline & MRI $(n=690)$ & $\mathrm{CT}(\mathrm{n}=1,321)$ & Available of $n=2,011$ & $p$ Value \\
\hline \multicolumn{5}{|l|}{ Clinical characteristics } \\
\hline Age, y & $72(60-80)$ & $74(62-82)$ & 2,011 & 0.003 \\
\hline Female & 351 (50.9) & $648(49.1)$ & 2,011 & 0.452 \\
\hline NIHSS on admission & $15(9-19)$ & $17(12-21)$ & 1,983 & $<0.001$ \\
\hline Transfer from another hospital & $171(24.9)$ & $547(41.4)$ & 2,009 & $<0.001$ \\
\hline Stroke onset & & & 2,011 & 0.281 \\
\hline Witnessed & $550(79.7)$ & $1,080(81.8)$ & & \\
\hline Unwitnessed & $140(20.3)$ & $241(18.2)$ & & \\
\hline Wake-up stroke & $67(11.3)$ & $92(7.1)$ & 1,894 & 0.003 \\
\hline Prestroke independence, mRS 0-2 & $645(95.1)$ & $1,206(91.9)$ & 1,990 & 0.007 \\
\hline Systolic blood pressure, $\mathrm{mm} \mathrm{Hg}$ & $153(134-173)$ & $148(130-165)$ & 1,447 & $<0.001$ \\
\hline Diastolic blood pressure, $\mathrm{mm} \mathrm{Hg}$ & $81(70-95)$ & $80(70-90)$ & 1,446 & 0.030 \\
\hline Admission glucose, $\mathrm{mmol} / \mathrm{L}$ & $6.6(5.7-7.9)$ & $6.8(5.8-8.3)$ & 1,487 & 0.021 \\
\hline \multicolumn{5}{|l|}{ Medication } \\
\hline Antiplatelet & & & 1,887 & 0.209 \\
\hline Mono & $187(32.1)$ & $367(28.1)$ & & \\
\hline Dual & $8(1.4)$ & $18(1.4)$ & & \\
\hline Statin & $133(27.1)$ & $377(31.0)$ & 1,706 & 0.115 \\
\hline Anticoagulation & & & 1,888 & $<0.001$ \\
\hline VKA & $43(7.4)$ & $175(13.4)$ & & \\
\hline DOAC & $18(3.1)$ & $55(4.2)$ & & \\
\hline \multicolumn{5}{|l|}{ Etiology } \\
\hline TOAST & & & 1,977 & $<0.001$ \\
\hline Large artery & $83(12.2)$ & $194(15.0)$ & & \\
\hline Cardioembolism & $269(39.4)$ & $644(49.7)$ & & \\
\hline Other specific & $44(6.5)$ & $97(7.5)$ & & \\
\hline Unknown & $286(41.9)$ & $360(27.8)$ & & \\
\hline \multicolumn{5}{|l|}{ Risk factors } \\
\hline Diabetes & $117(17.3)$ & $234(17.8)$ & 1,991 & 0.804 \\
\hline Arterial hypertension & $443(65.3)$ & $870(66.4)$ & 1,989 & 0.653 \\
\hline Dyslipidemia & $356(52.8)$ & $636(48.8)$ & 1,977 & 0.097 \\
\hline Smoking & $198(29.6)$ & $353(28.3)$ & 1,918 & 0.561 \\
\hline Previous stroke & $84(12.3)$ & $184(14.0)$ & 1,996 & 0.333 \\
\hline \multicolumn{5}{|l|}{ Imaging } \\
\hline CT/DWI ASPECTS & $8(5-9)$ & $9(7-10)$ & 1,698 & $<0.001$ \\
\hline Tandem occlusion & $99(14.4)$ & $207(15.7)$ & 2,009 & 0.472 \\
\hline Location & & & 2,004 & 0.003 \\
\hline
\end{tabular}


Table 1 Baseline characteristics of patients according to initial imaging modality (continued)

\begin{tabular}{llll}
\hline & MRI $(n=690)$ & CT $(n=1,321)$ & Available of $n=2,011 \quad 1,159(88.2)$ \\
\hline Anterior & $638(92.5)$ & $155(11.8)$ & $p$ Value \\
\hline Posterior & $52(7.5)$ &
\end{tabular}

Abbreviations: ASPECTS = Acute Stroke Prognosis Early CT Score; DOAC = direct oral anticoagulant; DWI = diffusion-weighted imaging; $\mathrm{mRS}=$ modified Rankin Scale; NIHSS = NIH Stroke Scale; TOAST = Trial of Org 10172 in Acute Stroke Treatment; VKA = vitamin K antagonist.

Results are presented as median (interquartile range) or absolute number (percentage).

combination of known predictors of FR following $\mathrm{EVT}^{2,5}$ and baseline and interventional differences of patients with and without FR factoring in the (multi) collinearity between variables (table 2, Dryad, doi.org/10.5061/dryad.f4qrff6t1). In a post hoc analysis, an ordinal shift analysis was applied using the same covariates and factors as stated above.

We excluded patients with missing data items from the multivariate analysis. For the sensitivity analysis, the same model was used to assess the association of imaging modality with FR defined as mRS 5-6 at 90 days, despite successful recanalization. We used a level of significance of 0.05. All analysis were performed with SPSS version 25 .

\section{Data availability}

Anonymized data will be shared by request from any qualified investigator after clearance by the ethics committee.

\section{Results}

\section{Baseline}

See figure 1 for the registry flowchart. The rates of FR were as follows: 38\% (571/1,489) FR mRS 4-6 including 26\% (393/ $1,489)$ FR mRS 5-6 and 62\% $(918 / 1,489)$ non-FR with mRS $0-3$ at 3 months. A total of 1,213/1,489 (81.5\%) patients were included in the primary multivariable analysis. Missing information on symptom onset to groin puncture (248) was the main missing data item.

Baseline characteristics and univariate comparisons of patients according to imaging modality are presented in table 1 .

Characteristics and univariate comparisons of patients with FR and without FR are presented in table 2. Patients with FR were older, were more often dependent before stroke onset, and had more severe stroke, higher glucose levels, less often witnessed symptom onset, a different cardiovascular risk profile, and more often a posterior circulation large vessel occlusion.

In the single-center analysis of the largest participating center, patients with MRI as the initial imaging modality had a lower crude proportion of subsequent MT as compared to CT $(61.8 \%$ vs $80.1 \%, p<0.001)$. However, after adjustments for baseline differences, MRI as compared to CT was not associated with a lower rate of subsequent MT (aOR 1.048, 95\% confidence interval [CI] 0.677-1.624). Of the baseline factors, NIHSS (aOR 1.198 95\% CI 1.156-1.241 per 1-point increase), posterior circulation large vessel occlusion (aOR 0.352 , 95\% CI $0.228-0.542$ ), preceding oral anticoagulation (aOR 2.610, 95\% CI 1.062-6.418), and treatment with IV thrombolysis (aOR $0.29695 \%$ CI $0.203-0.432$ ) were significantly associated with subsequent MT.

\section{Univariate analysis}

Univariate outcomes are presented in table 3. Patients selected by MRI as compared to CT had lower rates of FR $(28.6 \%$ [25\%-32\%] vs $43.8 \%$ [ $41 \%-47 \%], p<0.001)$. This finding remained consistent when only considering successfully recanalized patients with mRS 5-6 as FR (18.6\% $[15 \%-22 \%]$ vs $30.7 \%[28 \%-34 \%], p<0.001)$.

\section{Multivariate analysis}

According to the multivariable binary logistic regression analysis adjusting for prespecified confounders outlined in the Methods, CT was associated with increased odds for FR (aOR $1.770,95 \%$ CI 1.251-2.506, figure 2) as compared to MRI selection. This finding was consistent when using an ordinal shift analysis (aOR for the association of MRI with mRS $0.689,95 \%$ CI $0.556-0.854)$. In the sensitivity analysis considering patients with mRS 5-6 as futile, the point estimate was very similar (aOR 1.758, 95\% CI 1.197-2.583).

Of the prespecified confounders, age (per 1 year aOR 1.043, 95\% CI 1.031-1.055), NIHSS on admission (per 1 point aOR $1.087,95 \%$ CI 1.066-1.109), prestroke independence (aOR $0.239,95 \%$ CI $0.138-0.414$ ), diabetes (aOR 1.782 , 95\% CI $1.254-1.532$ ), and arterial hypertension (aOR $0.727,95 \% \mathrm{CI}$ 0.530-0.997) were associated with FR.

\section{Postinterventional model}

Also in the postinterventional multivariate model adjusting for additional interventional confounders, CT significantly increased the odds of having FR as compared to MRI selection (aOR $1.858,95 \%$ CI 1.285-2.687). Also in this model, the results were consistent when using an ordinal shift analysis (aOR for the association of MRI with mRS $0.639,95 \%$ CI $0.494-0.827$ ). Of the periinterventional confounders, complete recanalization TICI 3 (aOR 0.607, 95\% CI 0.432-0.853), intracranial stenting (aOR 2.620, 95\% CI 1.071-6.406), and maneuver count (per 1 pass aOR 1.253, 95\% CI 1.077-1.457) were associated with FR. 
Table 2 Baseline and interventional characteristics according to futility of recanalization

\begin{tabular}{|c|c|c|c|c|}
\hline & Futile $(n=571)$ & Nonfutile $(n=918)$ & Available of $n=1,489$ & $p$ Value \\
\hline \multicolumn{5}{|l|}{ Clinical characteristics } \\
\hline Age, y & $77(67-84)$ & $70(58-79)$ & 1,489 & $<0.001$ \\
\hline Female & 279/571 (48.9) & 438/918 (47.7) & 1,489 & 0.670 \\
\hline NIHSS on admission & $18(14-22)$ & $14(9-18)$ & 1,472 & $<0.001$ \\
\hline Transfer from another hospital & 198/571 (34.7) & 299/917 (32.6) & 1,488 & 0.429 \\
\hline Known time of symptom onset & $438 / 571(76.7)$ & 768/918 (83.7) & 1,489 & 0.001 \\
\hline Wake-up stroke & $52 / 539(9.6)$ & $65 / 858(7.6)$ & 1,397 & 0.197 \\
\hline Prestroke independence & $491 / 568(86.4)$ & $885 / 910(97.3)$ & 1,478 & $<0.001$ \\
\hline Systolic blood pressure, $\mathrm{mm} \mathrm{Hg}$ & 152 (SD 31) & 149 (SD 27) & 1,083 & 0.080 \\
\hline Diastolic blood pressure, $\mathrm{mm} \mathrm{Hg}$ & 80 (SD 19) & 82 (SD 19) & 1,082 & 0.097 \\
\hline Admission glucose, $\mathrm{mmol} / \mathrm{L}$ & $7.2(6.1-8.8)$ & $6.5(5.7-7.6)$ & 1,117 & $<0.001$ \\
\hline \multicolumn{5}{|l|}{ Medication } \\
\hline Antiplatelet & & & 1,403 & 0.257 \\
\hline Mono & $166 / 541(30.7)$ & 232/862 (26.9) & & \\
\hline Dual & $8 / 541(1.5)$ & $10 / 862(1.2)$ & & \\
\hline Statin & $153 / 485(31.5)$ & $211 / 770(27.4)$ & 1,255 & 0.125 \\
\hline Anticoagulation & & & 1,405 & 0.251 \\
\hline VKA & $64 / 544(11.8)$ & $84 / 861(9.8)$ & & \\
\hline DOAC & $28 / 544(5.1)$ & 34/861 (3.9) & & \\
\hline TOAST etiology & & & 1,472 & 0.188 \\
\hline Large artery & $81 / 566(14.3)$ & $128 / 906(14.1)$ & & \\
\hline Cardioembolism & 279/566 (49.3) & $415 / 906(45.8)$ & & \\
\hline Other specific & $31 / 566(5.5)$ & 75/906 (8.3) & & \\
\hline Unknown & 175/566 (30.9) & 288/906 (31.8) & & \\
\hline \multicolumn{5}{|l|}{ Risk factors } \\
\hline Diabetes & 120/564 (21.3) & $116 / 910(12.7)$ & 1,474 & $<0.001$ \\
\hline Arterial hypertension & $388 / 565(68.7)$ & $572 / 910(62.9)$ & 1,475 & 0.025 \\
\hline Dyslipidemia & 273/561 (48.7) & 459/907 (50.6) & 1,468 & 0.485 \\
\hline Smoking & $135 / 539(25.0)$ & $277 / 880(31.5)$ & 1,419 & 0.010 \\
\hline Previous stroke & $87 / 563(15.5)$ & $105 / 914(11.5)$ & 1,477 & 0.031 \\
\hline \multicolumn{5}{|l|}{ Modality } \\
\hline MRI & 152/571 (26.6) & $380 / 918(41.4)$ & 1,489 & $<0.001$ \\
\hline CT & $419 / 571(73.4)$ & 538/918 (58.6) & & \\
\hline CT/MRI ASPECTS & $8(6-9)$ & $8(7-10)$ & 1,247 & 0.001 \\
\hline Tandem occlusion & $80 / 570(14.0)$ & 135/917 (14.7) & 1,487 & 0.762 \\
\hline Location & & & & 0.004 \\
\hline Anterior & $489 / 569$ (85.9) & $831 / 915(90.8)$ & 1,484 & \\
\hline Posterior & $80 / 569(14.1)$ & $84 / 915(9.2)$ & 1,484 & \\
\hline
\end{tabular}


Table 2 Baseline and interventional characteristics according to futility of recanalization (continued)

\begin{tabular}{|c|c|c|c|c|}
\hline & Futile $(n=571)$ & Nonfutile $(n=918)$ & Available of $n=1,489$ & $p$ Value \\
\hline \multicolumn{5}{|l|}{ Treatment } \\
\hline IVT use & 253/571 (44.3) & $467 / 918(50.9)$ & 1,489 & 0.014 \\
\hline Time from onset of symptoms to IVT needle, $\min$ & $131(90-180)$ & $125(89-175)$ & $419 / 720$ & 0.470 \\
\hline Time from onset of symptoms to admission, $\mathrm{min}$ & $156(75-265)$ & $129(70-239)$ & 1,317 & 0.007 \\
\hline \multicolumn{5}{|l|}{ Procedure } \\
\hline Additional intraarterial thrombolytics & $45 / 537(8.4)$ & $62 / 852(7.3)$ & 1,389 & 0.470 \\
\hline Balloon guiding catheter & $251 / 539(46.6)$ & $425 / 857(49.6)$ & 1,396 & 0.272 \\
\hline Thrombectomy passes, $\mathbf{n}$ & $2(1-2)$ & $1(1-2)$ & 1,029 & $<0.001$ \\
\hline Intracranial stenting & $30 / 570(5.3)$ & $20 / 916(2.2)$ & 1,486 & 0.002 \\
\hline Extracranial stenting & $64 / 571(11.2)$ & $102 / 916(11.1)$ & 1,487 & 1.000 \\
\hline Time from onset of symptoms to groin puncture, min & $230(167-332)$ & $222(160-315)$ & 1,289 & 0.149 \\
\hline Time from groin to recanalization & $47(31-78)$ & $41(28-65)$ & 1,463 & $<0.001$ \\
\hline General anesthesia & $330 / 537(61.5)$ & $458 / 857(53.4)$ & 1,394 & 0.004 \\
\hline Interventional complication, any & $67 / 570(11.8)$ & $85 / 916(9.3)$ & 1,486 & 0.135 \\
\hline $\mathrm{TICl} 3$ & $301 / 571(52.7)$ & $532 / 918(58.0)$ & 1,489 & 0.053 \\
\hline
\end{tabular}

Abbreviations: ASPECTS = Acute Stroke Prognosis Early CT Score; DOAC = direct oral anticoagulant; IVT = IV thrombolysis; NIHSS = NIH Stroke Scale; TICI = Thrombolysis in Cerebral Infarction recanalization classification; TOAST = Trial of Org 10172 in Acute Stroke Treatment; VKA = vitamin K antagonist. Results are presented as median (interquartile range), mean (SD), or absolute number (percentage).

\section{Subgroup analyses}

Our main finding of an increased risk of FR in patients selected by CT were consistent throughout subgroups according to centers, anterior as compared to posterior circulation ( $p$ for interaction $=0.862)$, occlusion site, and low and high ASPECTS score (figure 3 and table 3, Dryad, doi.org/10. $5061 /$ dryad.f4qrfj6t1). When restricting the analysis to patients with known time of symptom onset, the increased risk of FR in patients selected by CT was robust also in patients presenting 0-6 hours after known symptom onset (aOR $1.757,95 \%$ CI 1.168-2.644) and the point estimate suggested an ever more pronounced association for patients presenting beyond 6 hours (aOR 24.6, 95\% CI 0.557-1.087), without reaching significance in this small subgroup. In patients with known symptom onset, there was no interaction of imaging type and presentation within 6 hours $(p=0.782)$.

\section{Secondary outcomes}

There was no difference in time from symptom onset to hospital admission between the imaging modalities (table 4). However, there was a time delay of 24 minutes from admission to groin puncture and 37 minutes from onset of symptoms to IVT needle in patients undergoing MRI. Rates of sICH were higher in patients selected with CT (7.0\% vs $4.4 \%$, $p=0.018)$, although this was nonsignificant after adjustments (aOR 1.087, 95\% CI 0.552-2.141). Rates of good functional outcome (mRS 0-2) were lower on univariate $(39.5 \%$ vs $50.1 \%, p<0.001$ ) and multivariable analysis (aOR 0.539, 95\%
CI 0.395-0.735) in patients selected with CT as compared to MRI. Fittingly, mortality at 3 months was higher in patients selected with CT on univariate $(28.1 \%$ vs $20.5 \%, p<0.001$ ) and multivariable analysis (aOR 1.613, 95\% CI 1.153-2.257). Additional analysis regarding influence of imaging modality on subsequent MT and pattern of vessel occlusions according to imaging modality and occurrence of FR are available from Dryad (tables 4-7, doi.org/10.5061/dryad.f4qrfj6t1).

\section{Discussion}

The main findings concerning the initial imaging selection modality for EVT in patients with acute ischemic stroke based on this multicenter registry analysis are as follows: (1) Compared to patients selected with CT, use of MRI was associated with a decreased risk of FR. (2) Patients selected by MRI have an unadjusted delay of roughly half an hour in workflow metrics in real-world university comprehensive stroke centers. (3) Nonetheless, as compared to patients selected with CT, functional outcome and mortality were more favorable in patients selected by MRI even after multivariable adjustments.

Despite the effectiveness of endovascular stroke treatment, the rate of FR remains very high. ${ }^{2}$ Hence, there is a need to reduce futile interventions ${ }^{4}$ to protect patients' autonomy and limit health care costs. Whether selection by MRI as opposed to $\mathrm{CT}$ actually results in a higher ${ }^{8,14}$ or a lower indication rate 
Table 3 Outcome data comparing patients according to initial imaging modality on univariate $\chi^{2}$ analysis

\begin{tabular}{|c|c|c|c|c|}
\hline Outcome & MRI & Ст & Available & $p$ Value \\
\hline Futile recanalization (mRS 4-6) & $152 / 532(28.6)$ & 419/957 (43.8) & $1,489 / 1,676$ & $<0.001$ \\
\hline Futile recanalization (mRS 5-6) & 99/532 (18.6) & 294/957 (30.7) & $1,489 / 1,676$ & $<0.001$ \\
\hline SICH ECASS II & $30 / 688(4.4)$ & $92 / 1,309(7.0)$ & $1,997 / 2,011$ & 0.018 \\
\hline mRS 0-3 & $424 / 665(63.8)$ & $602 / 1,130(53.3)$ & $1,795 / 2,011$ & $<0.001$ \\
\hline mRS 0-2 & $333 / 665(50.1)$ & $446 / 1,130(39.5)$ & $1,795 / 2,011$ & $<0.001$ \\
\hline mRS 0-1 & 218/665 (32.8) & $275 / 1,130(24.3)$ & $1,795 / 2,011$ & $<0.001$ \\
\hline Mortality & 136/665 (20.5) & $318 / 1,130(28.1)$ & $1,795 / 2,011$ & $<0.001$ \\
\hline
\end{tabular}

Abbreviations: $\mathrm{mRS}$ = modified Rankin Scale; sICH ECASS II = symptomatic intracranial hemorrhage according to the European Cooperative Acute Stroke Study II definition.

for $\mathrm{EVT}^{15}$ depends on the detailed imaging protocol, time from symptom onset to imaging, and decision algorithm. In our analysis, there was no influence of the initial imaging modality on MT rates.

In our analysis, MRI as the initial imaging modality compared to triage with $\mathrm{CT}$ was associated with a reduced rate of FR in highvolume comprehensive stroke centers. Several factors may explain this finding. First, MRI often provides more clear-cut information compared to CT ASPECTS and may facilitate treatment decisions in complex clinical scenarios. DWI as compared to CT perfusion, in particular, may provide a different estimate of the ischemic core, translating into improved individual patient selection in real-world clinical conditions. ${ }^{8,16,17}$ Moreover, MRI-selected patients seem to have a lower rate of $\mathrm{sICH}$, as also shown in a recent Korean study ${ }^{18}$ (see below), which may explain the lower frequency of FR, given the association between sICH and poor outcome.

Since the breakthrough of endovascular stroke therapy, indications to perform MT are constantly expanding, which may increase the rate of FR. Given the benefit of MT in almost all subgroup analyses, the role of imaging, at least in the early phase, is gradually shifting from selecting patients to deselecting patients. According to our results, MRI might be the more useful tool to identify patients who will most likely not benefit from EVT even in case of successful recanalization. Combining clinical factors like advanced age, prestroke dependency, high stroke severity, and expected time to recanalization with MRI-specific factors, such as large ischemic core volume, might lead to a predictive FR score in the future, which remains beyond the scope of the present study. The main concern in this context is that the use of MRI may lead to supraselection of eligible patients with AIS benefitting from MT. Machine learning and artificial intelligence represent promising tools to precisely determine whether MT will be beneficial or futile on an individual basis for patients with AIS, ${ }^{19,20}$ but until then, the positive predictive value of any simple "FR algorithm" should be as high as possible to avoid withholding an evidence-based treatment from otherwise suitable patients for endovascular recanalization therapies.

Figure 2 Unadjusted and adjusted odds ratios of outcomes for initial imaging selection with CT as compared to MRI

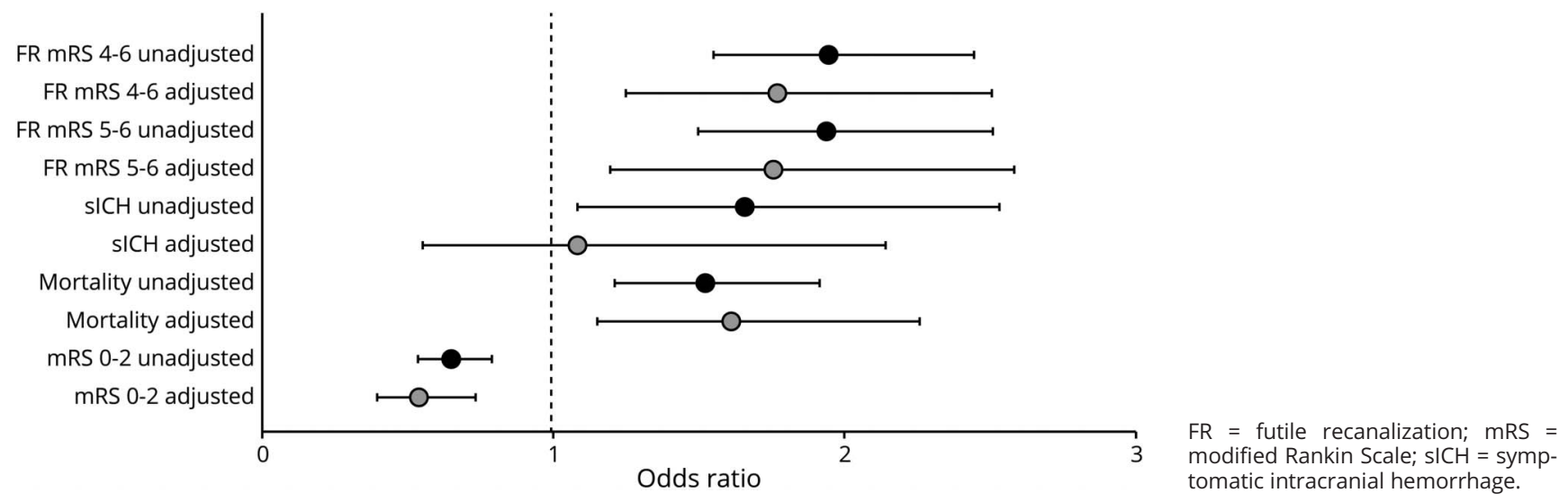


Figure 3 Subgroup analyses: Adjusted odds ratios of the multiple regression analysis for association of CT vs MRI with the primary outcome of futile recanalization

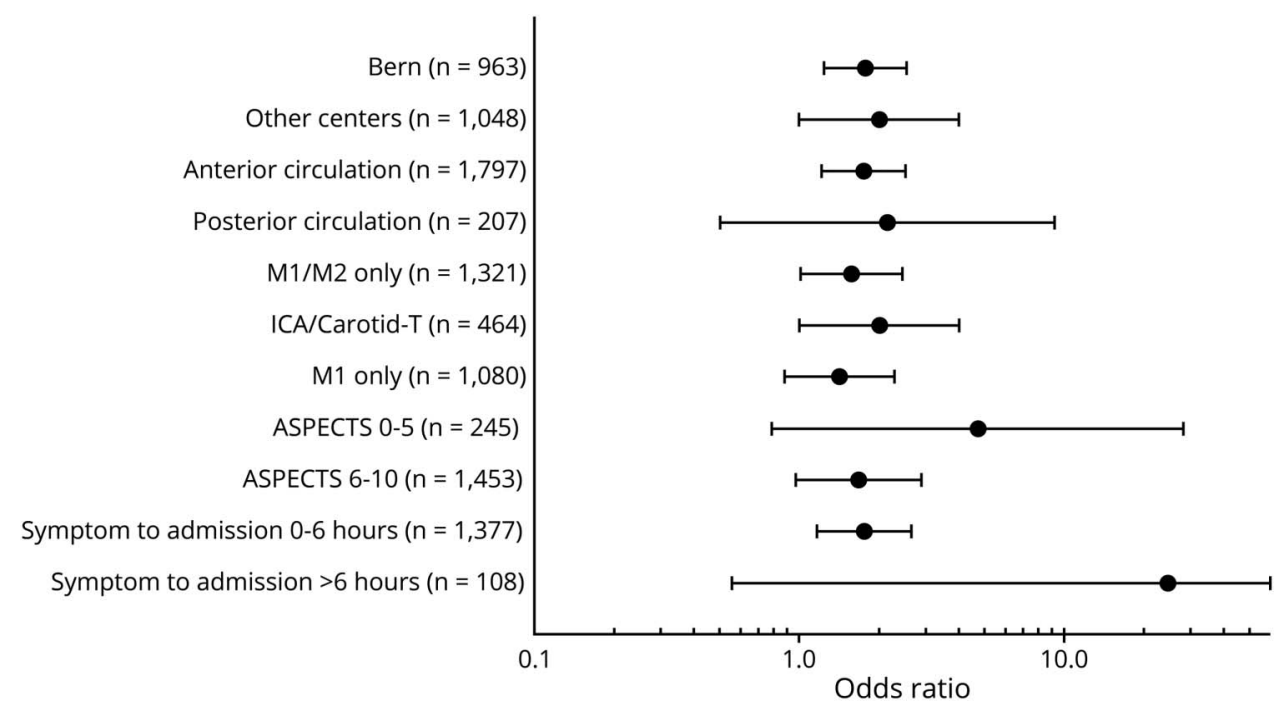

ASPECTS $=$ Alberta Stroke Program Early CT Score (1 point was added for MRI patients to control for the difference in diffusion-weighted imaging ASPECTS as compared to CT ASPECTS); ICA = internal carotid artery; $\mathrm{M} 1$ = middle cerebral artery 1 st segment; M2 = middle cerebral artery 2nd segment.
In randomized controlled trials (RCTs), no significant incenter delay was noted for patients undergoing MRI as compared to $\mathrm{CT},{ }^{21,22}$ although perfusion imaging was performed only in a minority of participants. ${ }^{22}$ Despite longer imaging duration, no impact on onset-to-needle and onset-togroin time was seen in those trials, possibly because of facilitated treatment decisions by DWI with clear-cut signal changes. The roughly 30-minute delay from admission to groin puncture in MRI-selected patients fits well with the reported data in real-world patients ${ }^{18}$ and underscores the importance to shorten in-hospital delays for MRI patients. However, MRI patients were less severely affected and hence had less clear indications for MT, like more distal occlusions.

In our dataset, there was a nonsignificant trend for sICH occurring less frequently in patients selected with MRI. A lower percentage of MRI-selected patients received IVT before MT, a finding that was nonsignificant in our registry, but significant in another recent observational study. ${ }^{18}$ After adjusting for possible confounders including the lower rate of IVT in MRI-selected patients, this association was nonsignificant in our registry, but remained significant in the study by Kim et al. ${ }^{18}$ Overall, in parallel to IVT, MRIselected MT patients appear to have an improved safety profile concerning $\mathrm{sICH}^{23,24}$ compared to those selected with CT. This might be explained by MRI being more sensitive to detect subtle hemorrhagic changes within the ischemic lesion ${ }^{25}$ or very severe white matter changes, and better estimation of the time elapsed in unknown or unwitnessed onsets, thereby allowing to withhold IVT in patients with higher risk to develop sICH.

Our finding of improved functional outcome at 3 months for MRI-selected patients is in line with data from the mostly early time window HERMES collaboration ${ }^{26}$ and late time window DEFUSE-3 (Diffusion and Perfusion Imaging Evaluation for Understanding Stroke Evolution Study 3) trials. ${ }^{27}$ Moreover, in SWIFT PRIME (Solitaire with the Intention for Thrombectomy as Primary Endovascular Treatment for Acute Ischemic Stroke), MRIselected patients had similar clinical and imaging outcomes as compared to CT perfusion-selected patients, despite worse prognostic characteristics. ${ }^{21}$ Nevertheless, assignment bias might have influenced those findings, since the choice of imaging was not randomized in any of the aforementioned trials. It is noteworthy that real-world studies have found no relevant difference in functional outcome ${ }^{18,21,22,27}$ between MRI- and CT-selected patients. Upcoming RCTs on this issue are on the horizon and will hopefully soon elucidate whether the type of imaging modality significantly influences outcome (IMAGECAT [Multimodal Neuroimaging in the Selection of Acute Ischemic Stroke (AIS) Patients to Endovascular Treatment (EVT)] [NCT03745391]). However, the main aim of this study was to sensitize stroke physicians that apparently the imaging modality influences their decisions regarding which patients to treat by MT. Whether this results in an overall better, worse, or equal outcome can only be judged by upcoming RCTs on this issue (IMAGECAT [NCT03745391]).

Given the large sample size and good quality data, we were able to include many preinterventional and postinterventional confounders in our model. Despite potential overadjustment, the association of MRI and reduced FR remained significant, arguing for a real effect. Of course, this study has the limitations of a multicenter, single-arm, retrospective registry of a highly selected patient population. 
Table 4 Workflow metrics of patients according to initial imaging modality

\begin{tabular}{|c|c|c|c|c|c|}
\hline & $\begin{array}{l}\text { MRI } \\
(n=690)\end{array}$ & $\begin{array}{l}\text { CT } \\
(n=1,321)\end{array}$ & Difference in minutes & $\begin{array}{l}\text { Available } n \\
\text { (total } n=2,011 \text { ) }\end{array}$ & $p$ Value \\
\hline \multicolumn{6}{|l|}{ Workflow metrics } \\
\hline Time from onset of symptoms to admission, $\min$ & $133(73-274)$ & $150(75-245)$ & 17 & 1,754 & 0.657 \\
\hline Time from onset of symptoms to IVT needle, $\min$ & $150(110-180)$ & $113(69-165)$ & 37 & $552 / 964$ & $<0.001$ \\
\hline Time from admission to groin puncture, $\min$ & $100(82-123)$ & $76(46-107)$ & 24 & 1,577 & $<0.001$ \\
\hline Time from onset of symptoms to groin puncture, $\min$ & $240(174-359)$ & $228(165-314)$ & 12 & 1,727 & 0.001 \\
\hline Time from groin to recanalization & $48(30-80)$ & $45(30-74)$ & 3 & 1,872 & 0.086 \\
\hline Time from symptom onset to recanalization & $300(225-409)$ & $282(215-375)$ & 18 & 1,619 & 0.005 \\
\hline
\end{tabular}

Abbreviation: IVT = IV thrombolysis.

Most importantly, patient triage with MRI or CT was centerspecific; reasons to prefer one imaging modality in individual patients was not available, and no medical comparison group was available. Hence inference on the overall influence of the imaging modality on the subsequent indication rate for MT are not possible. We sought to address this issue by including the treating center as categorical factor in the multivariable analysis. A major limitation of our study is the absence of core laboratory adjudicated recanalization grade, as well as preinterventional and postinterventional infarct volumes, among other factors. Moreover, the percentage of advanced perfusion studies and predictors shown to be associated with FR after EVT, including leukoaraiosis, ${ }^{7}$ were lacking. In addition, no information was available on the rate of angiography, although all centers confirmed that angiography was always intended and only skipped in cases of clinical problems (vomiting, agitation). Furthermore, more detailed workflow timepoints (admission to imaging time, imaging to puncture time) were not available, which hampers understanding differences in the workflow-related effects of each imaging modality. The date of the intervention was not known. However, the use of each imaging technique was consistent during the study period at each center and it is unclear how the expansion of indications for MT (e.g., more distal occlusions) might have influenced the occurrence of FR by each imaging modality. Finally, given the overall favorable prognostic profile of MRI patients, it remains possible that initial CT imaging might represent a surrogate marker of other residual confounding variables (frailty, offhour treatment, poor general condition, and patients with pacemakers) and selection bias might be present representing the true reason for increased rates of FR in those patients. Hence, our results need to be replicated by other groups and verified by upcoming RCTs on this issue (IMAGECAT [NCT03745391]).

Patient selection for MT by CT was associated with an increased risk of FR compared to MRI selection. Further research is needed to clarify the role of the initial imaging modality on FR occurrence and to develop a reliable FR prediction algorithm that could be included into shared decision-making and elucidation of patient preferences. Efforts are needed to shorten workflow delays in MRI patients. If confirmed in upcoming RCTs, cost-effectiveness analyses comparing CT with MRI as the best initial imaging modality for MT seem warranted due to the ambivalence between MRI-related costs and those associated with FR.

\section{Study funding}

The study was supported by Medtronic (Dublin, Ireland). Medtronic did not take part in the conception, design, or manuscript draft of this study.

\section{Disclosure}

T.R. Meinel reports no disclosures relevant to the manuscript. J. Kaesmacher reports grants from the Swiss Stroke Society and grants from SAMW/Bangerter Foundation during the conduct of the study. P.J. Mosimann reports no disclosures relevant to the manuscript. D. Seiffge reports other from Bayer Foundation outside the submitted work. S. Jung and P. Mordasini report no disclosures relevant to the manuscript. M. Arnold reports grants from the Swiss Heart Foundation; personal fees from Covidien, Medtronic, Bayer, BMS, Amgen, Daiichi Sankyo, and Nestle Health Sciences outside the submitted work. M. Olivé-Goeldlin reports grants from Bangerter-Rhyner-Foundation during the conduct of the study. S.D. Hajdu, M. Olivé-Gadea, and C. Maegerlein report no disclosures relevant to the manuscript. $\mathrm{V}$. Costalat reports grants from Medtronic, Stryker, Microvention, Cerenovus Penumbra, and Balt outside the submitted work. L. Pierot reports personal fees from Balt, Microvention, Phenox, and Vesalio outside the submitted work. J.D. Schaafsma reports no disclosures relevant to the manuscript. U. Fischer reports grants from Medtronic during the conduct of the study and other from Medtronic, Stryker, and CSL Behring outside the submitted work. J. Gralla reports grants from Medtronic and other from Penumbra outside the submitted work. Go to Neurology.org/ $\mathrm{N}$ for full disclosures. 


\section{Publication history}

Received by Neurology January 26, 2020. Accepted in final form May 18, 2020.

\section{Appendix Authors}

\begin{tabular}{|c|c|c|}
\hline Name & Location & Contribution \\
\hline $\begin{array}{l}\text { Thomas } \\
\text { Raphael } \\
\text { Meinel, MD }\end{array}$ & $\begin{array}{l}\text { Department of Neurology, } \\
\text { Inselspital, Bern University } \\
\text { Hospital, University of } \\
\text { Bern, Switzerland }\end{array}$ & $\begin{array}{l}\text { Drafting the manuscript, } \\
\text { study concept and design, } \\
\text { analysis and } \\
\text { interpretation of data, } \\
\text { acquisition of data, } \\
\text { statistical } \\
\text { analysis }\end{array}$ \\
\hline
\end{tabular}

\begin{tabular}{|c|c|c|}
\hline $\begin{array}{l}\text { Johannes } \\
\text { Kaesmacher, } \\
\text { MD }\end{array}$ & $\begin{array}{l}\text { Institute of Diagnostic and } \\
\text { Interventional } \\
\text { Neuroradiology, Institute } \\
\text { of Diagnostic, } \\
\text { Interventional and } \\
\text { Pediatric Radiology and } \\
\text { Department of Neurology, } \\
\text { University Hospital Bern, } \\
\text { Inselspital, University of } \\
\text { Bern, Switzerland }\end{array}$ & $\begin{array}{l}\text { Drafting the manuscript, } \\
\text { study concept and design, } \\
\text { analysis and } \\
\text { interpretation of data, } \\
\text { acquisition of data, } \\
\text { statistical analysis }\end{array}$ \\
\hline
\end{tabular}

\begin{tabular}{lll}
\hline Pascal John & Department of & Revising the manuscript, \\
Mosimann, & Neuroradiology, & interpretation of data \\
MD & Inselspital, Bern University & \\
& Hospital, University of & \\
& Bern, Switzerland &
\end{tabular}

\begin{tabular}{lll}
\hline David Seiffge, & $\begin{array}{l}\text { Department of Neurology, } \\
\text { Inselspital, Bern University } \\
\text { MD }\end{array}$ & $\begin{array}{l}\text { Revising the manuscript, } \\
\text { interpretation of data }\end{array}$ \\
& Hospital, University of & \\
& Bern, Switzerland &
\end{tabular}

Simon Jung Department of Neurology, Revising the manuscript,
Inselspital, Bern University interpretation of data Hospital, University of Bern, Switzerland

\begin{tabular}{|c|c|c|}
\hline $\begin{array}{l}\text { Pasquale } \\
\text { Mordasini, } \\
\text { MD }\end{array}$ & $\begin{array}{l}\text { Department of } \\
\text { Neuroradiology, } \\
\text { Inselspital, Bern University } \\
\text { Hospital, University of } \\
\text { Bern, Switzerland }\end{array}$ & $\begin{array}{l}\text { Revising the manuscript, } \\
\text { interpretation of data }\end{array}$ \\
\hline $\begin{array}{l}\text { Marcel } \\
\text { Arnold }\end{array}$ & $\begin{array}{l}\text { Department of Neurology, } \\
\text { Inselspital, Bern University } \\
\text { Hospital, University of } \\
\text { Bern, Switzerland }\end{array}$ & $\begin{array}{l}\text { Revising the manuscript, } \\
\text { interpretation of data }\end{array}$ \\
\hline $\begin{array}{l}\text { Martina } \\
\text { Goeldlin, MD }\end{array}$ & $\begin{array}{l}\text { Department of Neurology, } \\
\text { Inselspital, Bern University } \\
\text { Hospital, University of } \\
\text { Bern, Switzerland }\end{array}$ & $\begin{array}{l}\text { Revising the manuscript, } \\
\text { interpretation of data }\end{array}$ \\
\hline $\begin{array}{l}\text { Steven D. } \\
\text { Hajdu, MD }\end{array}$ & $\begin{array}{l}\text { Department of Radiology, } \\
\text { Lausanne University } \\
\text { Hospital, Switzerland }\end{array}$ & $\begin{array}{l}\text { Revising the manuscript, } \\
\text { interpretation of data, } \\
\text { data acquisition }\end{array}$ \\
\hline $\begin{array}{l}\text { Marta Olivé- } \\
\text { Gadea, MD }\end{array}$ & $\begin{array}{l}\text { Department of Neurology, } \\
\text { Vall d'Hebron University } \\
\text { Hospital, Barcelona, } \\
\text { Spain }\end{array}$ & $\begin{array}{l}\text { Revising the manuscript, } \\
\text { interpretation of data, } \\
\text { data acquisition }\end{array}$ \\
\hline $\begin{array}{l}\text { Christian } \\
\text { Maegerlein, } \\
\text { MD }\end{array}$ & $\begin{array}{l}\text { Department of Diagnostic } \\
\text { and Interventional } \\
\text { Neuroradiology, Klinikum } \\
\text { rechts der Isar, Technical } \\
\text { University Munich, } \\
\text { Germany }\end{array}$ & $\begin{array}{l}\text { Revising the manuscript, } \\
\text { interpretation of data, } \\
\text { data acquisition }\end{array}$ \\
\hline $\begin{array}{l}\text { Vincent } \\
\text { Costalat }\end{array}$ & $\begin{array}{l}\text { Department of } \\
\text { Neuroradiology, CHU } \\
\text { Montpellier, France }\end{array}$ & $\begin{array}{l}\text { Revising the manuscript, } \\
\text { interpretation of data, } \\
\text { data acquisition }\end{array}$ \\
\hline
\end{tabular}

Appendix (continued)

\begin{tabular}{|c|c|c|}
\hline Name & Location & Contribution \\
\hline $\begin{array}{l}\text { Laurent } \\
\text { Pierot }\end{array}$ & $\begin{array}{l}\text { Department of } \\
\text { Neuroradiology, CHU } \\
\text { Reims, France }\end{array}$ & $\begin{array}{l}\text { Revising the manuscript, } \\
\text { interpretation of data, } \\
\text { data acquisition }\end{array}$ \\
\hline $\begin{array}{l}\text { Joanna D. } \\
\text { Schaafsma, } \\
\text { MD }\end{array}$ & $\begin{array}{l}\text { Department of Neurology } \\
\text { Medicine, Division of } \\
\text { Neurology, Toronto } \\
\text { Western Hospital, Canada }\end{array}$ & $\begin{array}{l}\text { Revising the manuscript, } \\
\text { interpretation of data, } \\
\text { data acquisition }\end{array}$ \\
\hline Urs Fischer & $\begin{array}{l}\text { Department of Neurology, } \\
\text { Inselspital, Bern University } \\
\text { Hospital, University of } \\
\text { Bern, Switzerland }\end{array}$ & $\begin{array}{l}\text { Revising the manuscript, } \\
\text { study concept and design, } \\
\text { interpretation of data, } \\
\text { study supervision, } \\
\text { obtaining funding }\end{array}$ \\
\hline Jan Gralla & $\begin{array}{l}\text { Institute of Diagnostic and } \\
\text { Interventional } \\
\text { Neuroradiology, Institute } \\
\text { of Diagnostic, } \\
\text { Interventional and } \\
\text { Pediatric Radiology and } \\
\text { Department of Neurology, } \\
\text { University Hospital Bern, } \\
\text { Inselspital, University of } \\
\text { Bern, Switzerland }\end{array}$ & $\begin{array}{l}\text { Revising the manuscript, } \\
\text { study concept and design, } \\
\text { interpretation of data, } \\
\text { study supervision, } \\
\text { obtaining funding }\end{array}$ \\
\hline
\end{tabular}

\section{References}

1. Lindsberg PJ, Sairanen T, Nagel S, Salonen O, Silvennoinen H, Strbian D. Recanalization treatments in basilar artery occlusion: systematic analysis. Eur Stroke J 2016;1:41-50.

2. Hussein HM, Saleem MA, Qureshi AI. Rates and predictors of futile recanalization in patients undergoing endovascular treatment in a multicenter clinical trial. Neuroradiology 2018;60:557-563.

3. Ganesh A, Al-Ajlan FS, Sabiq F, et al. Infarct in a new territory after treatment administration in the ESCAPE randomized controlled trial (Endovascular Treatment for Small Core and Anterior Circulation Proximal Occlusion with Emphasis on Minimizing CT to Recanalization Times). Stroke 2016;47:2993-2998.

4. Molina CA. Editorial: Futile recanalization in mechanical embolectomy trials: a call to improve selection of patients for revascularization. Stroke 2010;41:842-843.

5. Park TH, Oh MS, Yeo M, et al. Futile reperfusion and predicted therapeutic benefits after successful endovascular treatment according to initial stroke severity. BMC Neurol 2019;19:1-9.

6. Alawieh A, Vargas J, Fargen KM, et al. Impact of procedure time on outcomes of thrombectomy for stroke. J Am Coll Cardiol 2019;73:879-890.

7. Gilberti N, Gamba M, Premi E, et al. Leukoaraiosis is a predictor of futile recanalization in acute ischemic stroke. J Neurol 2017;264:448-452.

8. Leslie-Mazwi TM, Hirsch JA, Falcone GJ, et al. Endovascular stroke treatment outcomes after patient selection based on magnetic resonance imaging and clinical criteria. JAMA Neurol 2016;73:43

9. Kaesmacher J, Chaloulos-Iakovidis P, Panos L, et al. Clinical effect of successful reperfusion in patients presenting with NIHSS $<8$ : data from the BEYOND-SWIFT Registry. J Neurol 2019;266:598-608.

10. Higashida RT, Furlan AJ, Roberts $\mathrm{H}$, et al. Trial design and reporting standards for intraarterial cerebral thrombolysis for acute ischemic stroke. J Vasc Interv Radiol 2003;14:E1-E31.

11. Nezu T, Koga M, Nakagawara J, et al. Early ischemic change on CT versus diffusionweighted imaging for patients with stroke receiving intravenous recombinant tissue-type plasminogen activator therapy: Stroke Acute Management with Urgent Risk-Factor Assessment and Improvement (SAMURAI) rt-PA registry. Stroke 2011;42:2196-2200.

12. Strbian D, Sairanen T, Silvennoinen H, Salonen O, Kaste M, Lindsberg PJ. Thrombolysis of basilar artery occlusion: impact of baseline ischemia and time. Ann Neurol 2013;73:688-694.

13. Hacke W, Kaste M, Fieschi C, et al. Randomised double-blind placebo-controlled trial of thrombolytic therapy with intravenous alteplase in acute ischaemic stroke (ECASS II). Lancet 1998;352:1245-1251.

14. DiBiasio EL, Jayaraman MV, Goyal M, et al. Dismantling the ability of CT and MRI to identify the target mismatch profile in patients with anterior circulation large vessel occlusion beyond six hours from symptom onset. Emerg Radiol 2019;26:401-408.

15. Wisco D, Uchino K, Saqqur M, et al. Addition of hyperacute MRI aids in patient selection, decreasing the use of endovascular stroke therapy. Stroke 2014;45:467-472.

16. Demeestere J, Garcia-Esperon C, Garcia-Bermejo P, et al. Evaluation of hyperacute infarct volume using ASPECTS and brain CT perfusion core volume. Neurology 2017;88:2248-2253.

17. Koopman MS, Berkhemer OA, Geuskens RREG, et al. Comparison of three commonly used CT perfusion software packages in patients with acute ischemic stroke. J Neurointerv Surg 2019;11:1249-1256. 
18. Kim JT, Cho BH, Choi $\mathrm{KH}$, et al. Magnetic resonance imaging versus computed tomography angiography based selection for endovascular therapy in patients with acute ischemic stroke. Stroke 2019;50:365-372.

19. McKinley R, Häni L, Gralla J, et al. Fully Automated Stroke Tissue Estimation Using Random Forest Classifiers (FASTER). J Cereb Blood Flow Metab 2017;37: 2728-2741.

20. Bang OY, Chung JW, Son JP, et al. Multimodal MRI-based triage for acute stroke therapy: challenges and progress. Front Neurol 2018;9:1-9.

21. Menjot De Champfleur N, Saver JL, Goyal M, et al. Efficacy of stent-retriever thrombectomy in magnetic resonance imaging versus computed tomographic perfusion-selected patients in SWIFT PRIME trial (Solitaire FR with the Intention for Thrombectomy as Primary Endovascular Treatment for Acute Ischemic Stroke). Stroke 2017;48:1560-1566.

22. Provost C, Soudant M, Legrand L, et al. Magnetic resonance imaging or computed tomography before treatment in acute ischemic stroke. Stroke 2019;50:659-664.
23. Köhrmann M, Jüttler E, Fiebach JB, et al. MRI versus CT-based thrombolysis treatment within and beyond the $3 \mathrm{~h}$ time window after stroke onset: a cohort study. Lancet Neurol 2006;5:661-667.

24. Schellinger PD, Thomalla G, Fiehler J, et al. MRI-based and CT-based thrombolytic therapy in acute stroke within and beyond established time windows: an analysis of 1210 patients. Stroke 2007;38:2640-2645.

25. Arnould MC, Grandin CB, Peeters A, Cosnard G, Duprez TP. Comparison of CT and three MR sequences for detecting and categorizing early (48 hours) hemorrhagic transformation in hyperacute ischemic stroke. AJNR Am J Neuroradiol 2004;25:939-944.

26. Campbell BCV, Majoie CBLM, Albers GW, et al. Penumbral imaging and functional outcome in patients with anterior circulation ischaemic stroke treated with endovascular thrombectomy versus medical therapy: a meta-analysis of individual patientlevel data. Lancet Neurol 2019;18:46-55.

27. Kemp S, Heit J, Albers GW, et al. Association of thrombectomy with stroke outcomes among patient subgroups. JAMA Neurol 2019;5778:1-7. 


\section{Neurology}

Association of initial imaging modality and futile recanalization after thrombectomy Thomas Raphael Meinel, Johannes Kaesmacher, Pascal John Mosimann, et al. Neurology 2020;95;e2331-e2342 Published Online before print August 26, 2020

DOI 10.1212/WNL.0000000000010614

This information is current as of August 26, 2020

Updated Information \& Services

References

Citations

Subspecialty Collections

Permissions \& Licensing

Reprints including high resolution figures, can be found at: http://n.neurology.org/content/95/17/e2331.full

This article cites 27 articles, 9 of which you can access for free at: http://n.neurology.org/content/95/17/e2331.full\#ref-list-1

This article has been cited by 2 HighWire-hosted articles: http://n.neurology.org/content/95/17/e2331.full\#\#otherarticles

This article, along with others on similar topics, appears in the following collection(s):

All Cerebrovascular disease/Stroke

http://n.neurology.org/cgi/collection/all_cerebrovascular_disease_strok e

\section{CT}

http://n.neurology.org/cgi/collection/ct

\section{Embolism}

http://n.neurology.org/cgi/collection/embolism

MRI

http://n.neurology.org/cgi/collection/mri

Information about reproducing this article in parts (figures,tables) or in its entirety can be found online at:

http://www.neurology.org/about/about_the_journal\#permissions

Information about ordering reprints can be found online:

http://n.neurology.org/subscribers/advertise

Neurology ${ }^{\circledR}$ is the official journal of the American Academy of Neurology. Published continuously since 1951, it is now a weekly with 48 issues per year. Copyright Copyright ( 2020 The Author(s). Published by Wolters Kluwer Health, Inc. on behalf of the American Academy of Neurology.. All rights reserved. Print ISSN: 0028-3878. Online ISSN: 1526-632X.

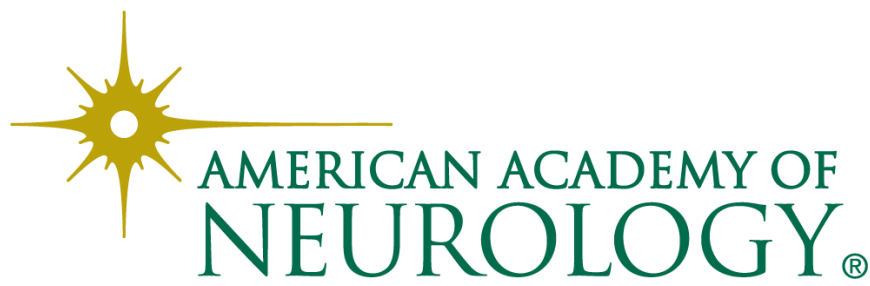

